\title{
Agility evaluation in public sector
}

\author{
Dahmardeh Nazar ${ }^{1}$, Pourshahabi Vahid ${ }^{2}$ \\ (1.Department of Economics, University of Sistan \& Baluchestan, Zahedan 9817734479, Iran; \\ 2. Department of Industrial Engineering, Azad University of Zahedan, Zahedan 9817734479, Iran)
}

\begin{abstract}
Agility metrics are difficult to define in general, mainly due to the multidimensionality and vagueness of the concept of agility itself. In this paper, a knowledge-based framework is utilized for the measurement and assessment of public sector's agility by A. T. Kearney model. In this research, the authors used $\chi^{2}$ test in SPSS software. So, the authors discovered that the General Office of Standards \& Industrial Research of Sistan \& Baluchestan Province in Iran is agile. Finally, the authors determine the weakness points of organization by Friedman test.
\end{abstract}

Key words: agility measuring; agile government; public sector

\section{Introduction}

Change and uncertainty dominate today's business environment. The competition is truly global, with fragmented markets and customers expecting to get the best product at service at the best price and with immediate availability. Success for a company is dependent on how well it can react and adapt to this environment. Meeting customer demands requires a high degree of flexibility, low-cost/low-volume manufacturing and service skills, and short delivery times (M. Jackson \& C. Johansson, 2002).

To maneuver in this environment and even thrive requires enterprises to not only accommodate the changing environment but also to seize the change and turn it to be the competitive advantage. Since the 1990s, researchers had recognized a need for this ability and named it agility (B. M. Arteta \& R. E. Giachetti, 2004).

Governments also need to respond to a changing and uncertain environment. However governments and corporations have distinct differences. Governments are accountable to citizens rather than shareholders; undertake activity that would be deemed unprofitable in private markets, and have the power to impose obligations and penalties. Nevertheless, the public sector is not immune to the factors that are driving the corporate sector to become more agile (Simon Parker \& Jamie Barlett, 2007).

Scientific literature provides only few specific studies proposing a structured framework to evaluating agility in public sector. This paper makes an attempt to fill this lack, by developing an integrated methodology for agility evaluation.

\section{A theoretical view of agility}

The concept of "agility" was introduced by researchers of the Iacocca Institute (1991) (Ching Trong Lin, Hero Chiu \& Po Young Chu, 2006), and since the first introduction, it has been receiving an increasing attention

Dahmardeh Nazar, Ph.D., Department of Economics, University of Sistan \& Baluchestan; research field: economics.

Pourshahabi Vahid, M.Sc., Department of Industrial Engineering, Azad University of Zahedan; research filed: industrial engineering. 
by both researchers and industrial communities. From 1990s until recently, many publications on the subject have appeared, which due to its newness, attempt to provide a definition of agility. Currently accepted definitions relate agility to the ability of companies to respond quickly and effectively to (unexpected) changes in market demand with the aim to meet varied customer requirements, in terms of price, specification, quality, quantity, and delivery. Agile enterprises react quickly and effectively to changing markets, driven by customized products and services. Moreover, agility directly affects company's capability to produce and deliver new products in a cost-efficient way. Decrease in manufacturing costs, increased customer satisfaction, removal of non-value added activities and increased competitiveness. Both of them are among benefits that can be achieved through agile strategies (Eleonora Bottani, 2009).

Goldman, et al (1995) describe four dimensions of agility as: (1) enriching the customer, (2) cooperating to enhance competitiveness, (3) organization to master change and uncertainty, (4) leveraging the impact of people and information. Many researchers focus more on the ability to respond to change (B. M. Arteta \& R. E. Giachetti, 2004).

Tsourveloudis and Valavanis (2002) say agility is more formally defined as the ability of enterprises to operate profitably in a rapidly changing and continuously fragmenting global market environment by producing high-quality, high-performance, customer-configured goods and services (Nikos C. Tsourveloudis \& Kimon P. Valavanis, 2002).

According to Zian, et al (2005), agility is a response to the challenges posed by business environment dominated by change and uncertainty. It involves a new way of doing business. It reflects a new mind-set on making, selling, and buying, openness to new forms of commercial relationships, and new measures for assessing the performance of companies and people (Mohamed Zain, Reduan Che Rose, Iskandar Abdollah \& Maslin Masrom, 2005). And Swafford, et al (2006), believe that agility is all about customer responsiveness and mastering market turbulence (Patricia M. Swafford, Soumen Ghosh \& Nagesh Murthy, 2006).

According to Sherehiy, et al (2007) agility is a successful application of competitive bases such as speed, flexibility, innovation, and quality by means of the integration of reconfigurable resources and best practices of knowledge-rich environment to provide customer-driven products and services in a fast changing environment (Bohdana Sherehiy, Waldemar Karwowski \& John K. Layer, 2007). Despite the differences, all definitions of "agility" emphasize the speed and flexibility as the primary attributes of an agile organization.

\subsection{Agile attributes}

Kidd (1994) suggests that agility can be achieved through the integration of organization, highly skilled and knowledgeable people and advanced technologies. A similar view is expressed by Goldman, et al (1995), and Gunasekaran (1998), who present "enriching the customer", "co-operation", "organizing to master change and uncertainty" and "leveraging the impact of people and information", as the four main dimensions of agility. Flexibility is also advocated as the basis of agility by Dove (1996), and, more recently, by Swafford, et al (2006). A comprehensive taxonomy of agile attributes was proposed by Yusuf, et al (1999), which identified 32 attributes characterizing an agile enterprise, ranging from "concurrent execution of activities", up to "employees satisfaction"; attributes were grouped into 10 decision domains. The set of agile attributes defined by Yusuf, et al (1999), has been exploited for many subsequent studies (Eleonora Bottani, 2009).

\subsection{Agile enablers}

One of the first attempts to provide a definition, as well as a comprehensive set, of agile enablers was made by Gunasekaran (1998). According to the author, agile enablers are enabling technologies which are critical to 
successfully accomplish agile manufacturing (August-Wilhelm Scheer, Helmut Kruppke, Wolfram Jost \& Herbert Kinderman, 2007). The author discusses seven agility enablers, namely "virtual enterprise formation tools/metrics", "physically distributed teams and manufacturing", "rapid partnership formation tools/metrics", "concurrent engineering", "integrated product/production/business information system", "rapid prototyping tools" and "electronic commerce".

Recently, a thorough review of agile strategies and technologies was performed by Gunasekaran and Yusuf (2002). As a result of their review, many enablers were added to the original ones: the authors identify about 60 viable leverages to implement agile manufacturing, which were categorized into 4 main sets, namely "strategic planning", "product design", "virtual enterprise" and "information technology" (Eleonora Bottani, 2009).

\section{Agile government}

Agile government has the capacity to understand and meet the public's needs in a short term, adapt to trends and issues in a medium term, and shape public needs over a long term. It recognizes the imperatives for ongoing reform and adaptation to deliver government policy, regulation, enforcement and services that continue to meet and anticipate societal needs (Simon Parker \& Jamie Barlett, 2008).

In today's world, the phrase "agile government" cannot be an oxymoron. Political, societal, economic and technological forces are affecting governments and their decisions with increasing speed. Citizens and businesses demand faster and more personalized service, and policies must be developed and implemented more quickly than before (A. T. Kearney, Inc., 2003).

In 2006, the State Services Authority released a report on The Future of the Public Sector in 2025. The report identified seven future issues and challenges for the public sector. One of these was fostering agility to support a high performing public sector. The uncertainty that the future holds means that the public sector cannot predict all the challenges that it will confront. As such, the public sector requires agility in its systems and structures to respond to future issues.

In government, agility means understanding and meeting the needs of citizens in a short term, adapting structures and services to address medium term trends, and shaping needs in a long term. In practice, an agile government needs to develop its capacity in the following areas:

- Short term responsiveness - responding to the public's day to day needs through choice, voice and personalization.

- Strategic adaptation-learning from and scaling up innovation to improve public service systems over the long run.

- Outcomes focus - focusing on end results to address cross-cutting issues.

- Long term shaping - positively intervening in society to affect long term trends, creating new opportunities and preventing or reducing problems before they arise (Simon Parker \& Jamie Barlett, 2008).

\subsection{Model of agile government}

In 2003, A. T. Kearney embarked on research initiative to better understand how government departments and agencies in eight OECD (Organization for Economic Cooperation and Development) countries are working to become more agile and to understand the relationship between agility, and success in meeting the demands of modern government. In partnership with the Public Policy Group of the London School of Economics, A. T. Kearney conducted in-depth surveys and interviews with government agency leaders and senior civil servants who 
design and implement change strategies, and presented this model (see Fig. 1).

- Create an environment that promotes change

- Look beyond immediate needs to invest in innovation

- Build a sense of teamwork throughout the organization

- Focus on training people for future performance

- Establish an organization-wide performance management system

- Use a balanced scorecard to measure performance
- Establish a clear vision for the organization

- Focus on new trends and strategic goals

- Increase flexibility and apply resources where and when they are needed most

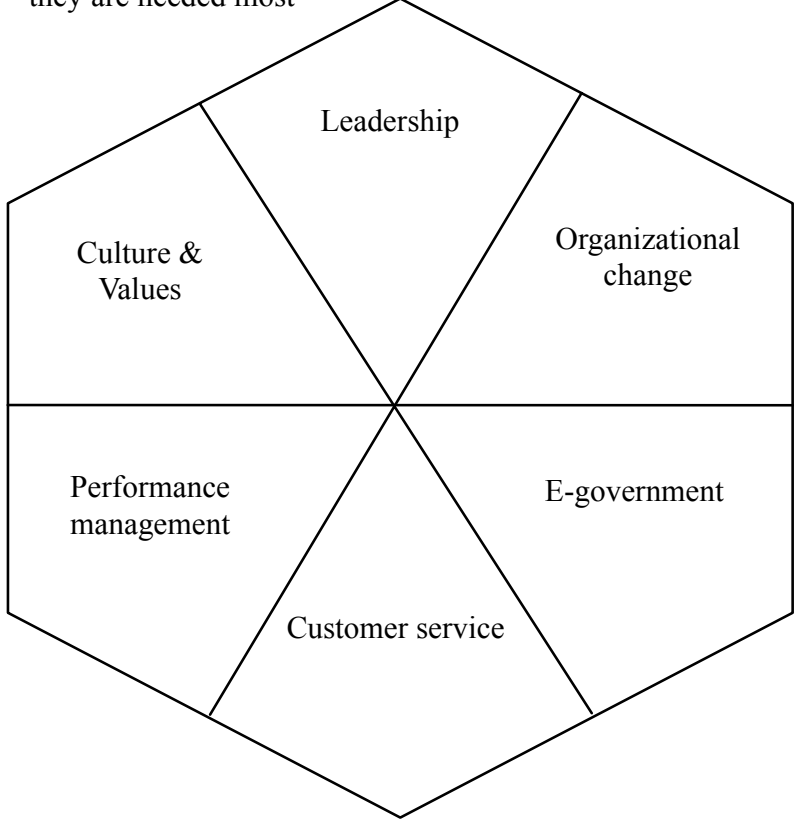

- Establish a customer relationship management strategy

- Align customer service with business processes

- Offer customers incentives to move to new, less expensive channels (for example, online systems)
- Understand customer's needs

- Improve customer service

- Reach decisions through consensus

- Assign resources as necessary to meet customer's needs

- Move to electronic processes

- Use technology to improve communication among agencies

- Encourage customers to move to more cost-efficient channels

Fig. 1 The model of agile government

Data source: A. T. Kearney (2003, June).

\section{Case study}

This section cites the agility evaluation of a General Office of Standards \& Industrial Research of Sistan \& Baluchistan Province in Iran to measure agility in public sector.

\subsection{Method of research}

In this research we used hypothesis test to demonstrate that the General Office of Standards \& Industrial Research of Sistan \& Baluchistan Province in Iran is agile. So we determined six hypothesizes that obtained from A. T. Kearney model:

(1) From Leadership dimension, General Office of Standards and Industrial Research is agile;

(2) From Culture and Values dimension, General Office of Standards and Industrial Research is agile;

(3) From Customer Service dimension, General Office of Standards and Industrial Research is agile;

(4) From E-Government dimension, General Office of Standards and Industrial Research is agile;

(5) From Performance Management dimension, General Office of Standards and Industrial Research is agile;

(6) From Organizational Change dimension, General Office of Standards and Industrial Research is agile.

Our sample wrought 40 experts from staff of General Office of Standards and Industrial Research of Sistan 
and Baluchistan Province in Iran. And we collected data by questionnaires with 30 questions. Moreover, the Cronbach Alpha of the questionnaire calculated by SPSS software in 0.9740. So, the outcomes of hypothesis tests by SPSS $\chi^{2}$ test are displayed in Table 1. As a result, the entire hypothesis was accepted. Thus, the General Office of Standards and Industrial Research is agile.

Table 1 Results of hypothesis test

\begin{tabular}{|c|c|c|c|c|c|}
\hline \multirow{2}{*}{ No. } & \multicolumn{2}{|c|}{ Variables } & \multirow{2}{*}{ df. } & \multirow{2}{*}{ Sig. } & \multirow{2}{*}{ Test results } \\
\hline & Independent variables & Dependent variable & & & \\
\hline 1 & Leadership & \multirow{6}{*}{ Agility } & 3 & 0.002 & $\mathrm{H}_{0}$ rejection \\
\hline 2 & Culture \& Values & & 6 & 0.025 & $\mathrm{H}_{0}$ rejection \\
\hline 3 & Customer service & & 4 & 0.013 & $\mathrm{H}_{0}$ rejection \\
\hline 4 & E-government & & 4 & 0.006 & $\mathrm{H}_{0}$ rejection \\
\hline 5 & Performance management & & 3 & 0.001 & $\mathrm{H}_{0}$ rejection \\
\hline 6 & Organizational change & & 4 & 0.043 & $\mathrm{H}_{0}$ rejection \\
\hline
\end{tabular}

To determine the weakness points of this organization (Rick Hefner \& Northrop Grumman, 2006), we used Friedman test of SPSS software. The results of Friedman test are displayed in Table 2.

Table 2 Results of Friedman test

\begin{tabular}{|c|c|}
\multicolumn{2}{c}{ Ranks } \\
\hline & Mean rank \\
\hline Q1 & 2.14 \\
Q2 & 3.04 \\
Q3 & 2.43 \\
Q4 & 2.39 \\
\hline
\end{tabular}

\begin{tabular}{|c|c|}
\multicolumn{2}{c}{ Ranks } \\
\hline & Mean rank \\
\hline Q5 & 3.54 \\
Q6 & 4.11 \\
Q7 & 3.85 \\
Q8 & 4.88 \\
Q9 & 3.71 \\
Q10 & 4.43 \\
Q11 & 3.49 \\
\hline
\end{tabular}

\begin{tabular}{|c|c|}
\multicolumn{1}{c}{ Ranks } \\
\hline & Mean rank \\
\hline Q12 & 2.93 \\
Q13 & 3.64 \\
Q14 & 2.72 \\
Q15 & 2.67 \\
Q16 & 3.04 \\
\hline
\end{tabular}

\begin{tabular}{|c|c|}
\multicolumn{2}{c}{ Ranks } \\
\hline & Mean rank \\
\hline Q17 & 3.50 \\
Q18 & 2.93 \\
Q19 & 2.35 \\
Q20 & 3.01 \\
Q21 & 3.21 \\
\hline
\end{tabular}

\begin{tabular}{|c|c|}
\multicolumn{2}{c}{ Ranks } \\
\hline & Mean rank \\
\hline Q22 & 2.38 \\
Q23 & 2.01 \\
Q24 & 3.04 \\
Q25 & 2.57 \\
\hline
\end{tabular}

\begin{tabular}{|c|c|}
\multicolumn{2}{c}{ Ranks } \\
\hline & Mean rank \\
\hline Q26 & 3.29 \\
Q27 & 2.65 \\
Q28 & 2.57 \\
Q29 & 3.10 \\
Q30 & 3.39 \\
\hline
\end{tabular}

\section{Conclusion}

Agility is the ability of an organization to adapt to change and also to seize opportunities that become available due to change. And in government, agility means understanding and meeting the needs of citizens in a short term, adapting structures and services to address medium term trends, and shaping needs in a long term.

Based on the results of this paper, we submit 5 solutions to increase the agility level of the General Office of Standards and Industrial Research of Sistan and Baluchistan Province. The key to increasing organizational agility 
in this organization is improving this attributes: (1) Notation clear vision for organization; (2) Setting needful information in web site; (3) Possibility of E-Consultation for customers; (4) Instruction people for future works; (5) Implementation of new technologies in producing services.

\section{References:}

A. T. Kearney, Inc. (2003). Improving performance in public sector.

August-Wilhelm Scheer, Helmut Kruppke, Wolfram Jost \& Herbert Kinderman. (2007). Agility, ARIS business process management. Berlin: Springer.

B. M. Arteta \& R. E. Giachetti. (2004). A measure of agility as the complexity of the enterprise system. Robotics and Computer Integrated Manufacturing, 20(6), 495-503.

Bohdana Sherehiy, Waldemar Karwowski \& John K. Layer. (2007). A review of enterprise agility: Concepts, frameworks, and attributes. International Journal of Industrial Ergonomics, 37(5), 445-460.

Ching Trong Lin, Hero Chiu \& Po Young Chu. (2006). Agility index in the supply chain. Int. J. Production Economics, 100(2), 285-299.

Eleonora Bottani. (2009). A fuzzy QFD approach to achieve agility. International Journal of Production Economics, 119(2), $380-391$.

M. Jackson \& C. Johansson. (2002). An agility analysis from a production system perspective. Integrated Manufacturing Systems, 14(6), 482-488.

Mohamed Zain, Reduan Che Rose, Iskandar Abdollah \& Maslin Masrom. (2005). The relationship between information technology acceptance and organizational agility in Malaysia. Information and Management, 42(6), 829-839.

Nikos C. Tsourveloudis \& Kimon P. Valavanis. (2002). On the measurement of enterprise agility. Journal of Intelligent and Robotics Systems, 33(3), 329-342.

Patricia M. Swafford, Soumen Ghosh \& Nagesh Murthy. (2006). The antecedents of supply chain agility of a firm: Scale development and model testing. Journal of Operations Management, 24(2), 170-188.

Rick Hefner \& Northrop Grumman. (2006). Six sigma applied throughout the lifecycle of an automated decision system. Quality and Reliability Engineering International, 21(3), 275-292.

Simon Parker \& Jamie Barlett. (2008). Toward agile government. State service authority.

(Edited by Ruby and Gracie)

(continued from Page 37)

\section{References:}

HUANG Xiao-ying. (2007). Credit card economics-From the cost factors of income to see credit card profit model. Financial Electronic, 10.

LI Hui-yan. (2007 April). China’s commercial banks credit card business, profitability analysis. (Master's dissertation, Suzhou University).

LIN Xiao-ning. (2007). China's credit card industry, the profitability of pattern analysis. Modern Trade Industry, 11.

TANG Fang. (2007). Based on rule-based costing credit card customer profitability analysis. Financial Accounting, 9.

YANG Xiao-li. (2007, June). China's credit card profit model discussion. (Master's dissertation, Nanjing University of Science).

ZHAO Zhi-hong. (2005). Credit risk management and profit increase. Bankers, 8.

(Edited by Ruby and Gracie) 